\title{
Zinc Electrode Morphology Evolution in High Energy Density Nickel-Zinc Batteries
}

\author{
Gizem Payer and Özgenç Ebil \\ Department of Chemical Engineering, Izmir Institute of Technology, Urla, 35430 Izmir, Turkey \\ Correspondence should be addressed to Özgenç Ebil; ozgencebil@iyte.edu.tr
}

Received 4 January 2016; Accepted 25 February 2016

Academic Editor: Mohamed Bououdina

Copyright (c) 2016 G. Payer and Ö. Ebil. This is an open access article distributed under the Creative Commons Attribution License, which permits unrestricted use, distribution, and reproduction in any medium, provided the original work is properly cited.

Prismatic Nickel-Zinc (NiZn) batteries with energy densities higher than $100 \mathrm{Wh} \mathrm{kg}^{-1}$ were prepared using Zn electrodes with different initial morphologies. The effect of initial morphology of zinc electrode on battery capacity was investigated. Scanning electron microscopy (SEM) and X-ray diffraction (XRD) reveal that initial morphology of zinc electrode changes drastically after a few charge/discharge cycles regardless of initial $\mathrm{ZnO}$ powder used. $\mathrm{ZnO}$ electrodes prepared using $\mathrm{ZnO}$ powders synthesized from $\mathrm{ZnCl}_{2}$ and $\mathrm{Zn}\left(\mathrm{NO}_{3}\right)_{2}$ lead to average battery energy densities ranging between $92 \mathrm{Wh} \mathrm{kg}^{-1}$ and $109 \mathrm{Wh} \mathrm{kg}^{-1}$ while using conventional $\mathrm{ZnO}$ powder leads to a higher energy density, $118 \mathrm{Wh} \mathrm{kg}^{-1}$. Average discharge capacities of zinc electrodes vary between 270 and $345 \mathrm{~mA} \mathrm{~g}^{-1}$, much lower than reported values for nano $\mathrm{ZnO}$ powders in literature. Higher electrode surface area or higher electrode discharge capacity does not necessarily translate to higher battery energy density.

\section{Introduction}

Nickel-Zinc (NiZn) batteries are one of the oldest but still promising electrochemical energy storage solutions for hybrid/electric vehicles and portable electrical/electronic devices. Commercially available NiZn batteries exhibit moderate specific energy $\left(55-85 \mathrm{Wh} \mathrm{kg}^{-1}\right)$, high power density $\left(140-200 \mathrm{Wh} \mathrm{kg}^{-1}\right)$, high open circle potential $(1.705 \mathrm{~V})$, and a nominal cell voltage of $1.6 \mathrm{~V}$ which is greater than that of $\mathrm{NiCd}$ and NiMH batteries $[1,2]$. Furthermore, compared to readily available battery technologies such as $\mathrm{Li}$-ion, $\mathrm{NiCd}$, and NiMH, NiZn batteries provide a low-cost and environmentally friendly alternative with comparable if not better performance per unit weight. However, NiZn technology has not reached its full potential due to a variety of issues that are well documented in literature [3-5]. Among these issues are the shape change of zinc electrode with increasing charge/ discharge cycle count, zinc electrode passivation, and dendritic zinc growth leading to short-circuiting of the battery. In discharge process, zinc is dissolved as zincate ion $\left(\mathrm{Zn}(\mathrm{OH})_{4}{ }^{2-}\right)$ in alkaline electrolyte before zinc oxide precipitates. Highly mobile zincate ions are concentrated near the bottom of the electrode and precipitate as zinc oxide when solubility limit is reached. This process leads to thickness nonuniformity of deposited zinc on the electrode with increasing charge/discharge cycle count and, combined with the dendritic growth of zinc during charging, eventually causes short-circuiting of the battery. Passivation is also considered as one of the serious issues for the deterioration of zinc batteries. This phenomenon occurs when the dissolution of zinc produces a situation in which the solubility limit of zincate is reached in electrolyte close to the surface of the zinc electrode, and a zinc oxide insulating layer is formed on the electrode surface. As a result of these issues, short cycle life and/or poor electrochemical performance have limited large-scale implementation of NiZn batteries [3, 6-8]. Some of these issues are directly or indirectly related to formation of soluble zincate ions in alkaline solution during battery operation. The solubility limit of zincate is determined by the temperature and $\mathrm{pH}$ of alkaline solution. Many attempts have been made to minimize the solubility and movement of zinc oxidation products in alkaline solutions and to improve physical and chemical stability of zinc electrode with increasing charge/discharge cycle count. These attempts include but not limited to using organic and inorganic additives in zinc electrode and electrolyte, tailoring separator 
structure to minimize dendritic zinc growth $[9,10]$, and using different electrode geometries [11, 12]. One of the effective ways to minimize the abovementioned problems is to use various oxide additives, such as $\mathrm{Ca}(\mathrm{OH})_{2}[13,14], \mathrm{Bi}_{2} \mathrm{O}_{3}[15]$, $\mathrm{PbO}$ [16], $\mathrm{TiO}_{2}$ [17], and $\mathrm{In}_{2} \mathrm{O}_{3}$ [18], in zinc electrode. These additives can reduce the concentration of the zinc oxidation products and improve electronic conductivity and current distribution [14]. Binders or gels, such as sodium silicate [19], tapioca [20], polytetrafluoroethylene [21, 22], Carbopol gel $[23,24]$, and sago which is a starch extracted from palm stems [25], were used to increase the active material utilization and effective surface area in zinc electrode. Addition of sodium silicate as binder was reported to increase battery performance [19]. It was also reported that using tapioca starch as binder for porous zinc electrode enhances specific capacity [20]. A variety of organic additives are used in alkaline solutions as zinc corrosion inhibitors. Some of them are either expensive or toxic and not environmentally friendly limiting their use in batteries. One of the few organic materials which is nontoxic and cheap is polyethylene glycol (PEG) $[26,27]$. Corrosion inhibition capability of PEG was found to be greater than that of polyoxyethylene alkyl phosphate ester acid form when used in zinc electrode [27, 28]. Although partially successful, none of the attempts in literature has provided an ultimate solution for short life and poor performance of zinc electrode due to the shape change and short-circuiting as a result of dendritic zinc growth during charging.

In addition to using additives, it was initially thought that, by carefully controlling the morphology of the electrode, it would be possible to minimize the shape change of zinc electrode. $\mathrm{ZnO}$ particles with various morphologies (nanowires, hexagonal nanorods, etc.) can be produced by using different methods [29-31]. There are several studies in literature on the effect of the initial morphology of zinc electrode on the electrochemical performance of the battery $[6-8,32,33]$. Some of these studies focused on controlling zinc electrode morphology by using $\mathrm{ZnO}$ nanowires, nanorods, and fibers. For example, Yang et al. investigated $\mathrm{ZnO}$ nanowires synthesized by hydrothermal method as electrode material [32]. It was reported that nanowire structures broke and changed into nanorods throughout charging/discharging cycles and suppressed the growth of dendritic zinc. The use of prismatic $\mathrm{ZnO}$ synthesized by homogeneous precipitation as electrode material was investigated by Yuan et al. [8]. The results showed that the midpoint discharge voltage, cycle stability, and passivation toleration were improved compared to commercial $\mathrm{ZnO}$ with typical hexagonal prism particles. Yuan and coworkers examined the effect of morphology and size of $\mathrm{ZnO}$ on the performance of zinc electrode in detail [6]. Compared to other morphologies, nanorod $\mathrm{ZnO}$ particles exhibited the better electrochemical cycle stability and charge/discharge performance. Their results showed that conventional hexagonal $\mathrm{ZnO}$ particles were converted into flaky crystals, which decreased performance. Wen and coworkers reported that electrochemical performance of the hollow fusion $\mathrm{ZnO}$ and the hexagonal taper-like $\mathrm{ZnO}$ prepared by hydrothermal method were greater compared to conventional $\mathrm{ZnO}$ as anodic materials for $\mathrm{NiZn}$ cells, and hollow fusion $\mathrm{ZnO}$ particles showed the best electrochemical cycle stability and charge/discharge performance [33].

Herein, we present prismatic NiZn batteries with different initial zinc electrode morphologies, having energy densities in Li-ion territory, above $100 \mathrm{Wh} \mathrm{kg}^{-1}$. $\mathrm{ZnO}$ powders for zinc electrodes were synthesized from different precursors, $\mathrm{ZnCl}_{2}$ and $\mathrm{Zn}\left(\mathrm{NO}_{3}\right)_{2} \cdot 6 \mathrm{H}_{2} \mathrm{O}$. Combined with conventional $\mathrm{ZnO}$ powder commonly used in commercial NiZn batteries, effect of initial zinc electrode morphology on battery capacity was investigated.

\section{Experimental}

2.1. Preparation of $\mathrm{ZnO}$ Powders. Three different $\mathrm{ZnO}$ powders were used in this study. In addition to commercial $\mathrm{ZnO}$ powder produced by mechanochemical methods at elevated temperatures (Kimetsan, 99\%), two other $\mathrm{ZnO}$ powders with different morphologies were synthesized as described below.

2.1.1. $\mathrm{ZnO}$ Powder Synthesis from $\mathrm{ZnCl}_{2}$. Nanosized spherical $\mathrm{ZnO}$ particles were prepared by a simple precipitation method as described in literature [34]. The total of $100 \mathrm{~mL}$ solution containing 0.2 M KOH (Merck) and $0.02 \mathrm{M}$ triethanolamine (TEA) (Kimetsan, 99\%) as surfactant was slowly added to $100 \mathrm{~mL} 0.1 \mathrm{M} \mathrm{ZnCl}_{2}$ (Merck) solution under strong mechanical stirring. Ultrasonic treatment (WUC$\mathrm{D} 06 \mathrm{H}$, Wisd) was performed for $45 \mathrm{~min}$ at $50^{\circ} \mathrm{C}$. The precipitate was separated from liquid phase by centrifuging (Sigma, $3-16 \mathrm{PK}$ ) at $4000 \mathrm{rpm}$ for $5 \mathrm{~min}$. The solid phase was then washed with $500 \mathrm{~mL} 0.1 \mathrm{M} \mathrm{NH}_{4} \mathrm{OH}$ (Sigma Aldrich, 28-29\%) solution three times. Finally, the solid phase was dried at $50^{\circ} \mathrm{C}$ for $15 \mathrm{~h}$ and then baked at $200^{\circ} \mathrm{C}$ for $2 \mathrm{~h}$ in oven.

2.1.2. $\mathrm{ZnO}$ Powder Synthesis from $\mathrm{Zn}\left(\mathrm{NO}_{3}\right)_{2}$. Nanosized plate-like $\mathrm{ZnO}$ particles were prepared by a simple precipitation method as commonly used in literature [35]. The total of $27.85 \mathrm{~mL}$ of $8 \mathrm{M} \mathrm{NaOH}$ (Merck, 98\%) was slowly added to $100 \mathrm{~mL}$ of $1 \mathrm{M} \mathrm{Zn}\left(\mathrm{NO}_{3}\right)_{2} \cdot 6 \mathrm{H}_{2} \mathrm{O}$ (Scharlau, 98\%) solution under mechanical stirring at $20^{\circ} \mathrm{C}$. Ultrapure water $(22.15 \mathrm{~mL})$ was then added to the mixture to obtain a $\mathrm{pH}$ value around 13 and the solution was aged at $20^{\circ} \mathrm{C}$ for $30 \mathrm{~min}$. The precipitate was separated from liquid phase by centrifuging at $4000 \mathrm{rpm}$ for $5 \mathrm{~min}$. The solid phase was washed with ultrapure water three times. Finally, the solid phase was dried at $50^{\circ} \mathrm{C}$ for $20 \mathrm{~h}$ and then baked at $200^{\circ} \mathrm{C}$ for $2 \mathrm{~h}$ in oven.

2.2. Preparation of Prismatic Batteries. Prismatic NiZn batteries with zinc electrodes having different initial $\mathrm{ZnO}$ powder morphologies were prepared for evaluation of $\mathrm{Zn}$ electrode morphology change during battery operation and its effect on battery capacity. Zinc electrode paste was prepared by mechanically mixing $3 \mathrm{~g}$ zinc oxide powder, $0.03 \mathrm{~g}$ calcium hydroxide, and $0.08 \mathrm{~g}$ lead (II) oxide, with previously prepared $1 \mathrm{~mL} \mathrm{10 \%} \mathrm{PEG} \mathrm{and} 1.6 \mathrm{~mL} 6 \mathrm{M} \mathrm{KOH}$ solutions containing $0.35 \mathrm{~g}$ dissolved cellulose. The paste was then applied onto one side of $40 \mu \mathrm{m}$ thick tin-electroplated nickel current collector using a stencil to form a uniform layer. Pasted $\mathrm{Ni}(\mathrm{OH})_{2}$ electrodes with twice the capacity of $\mathrm{Zn}$ electrodes 
were used to make sure that the battery capacity was not limited by Ni electrode. Ni electrode paste was applied to both sides of a Ni foil current collector using a stencil. Commercial cellulose based separators (Ocalı A. S.) were liberally wetted with $6 \mathrm{M} \mathrm{KOH}$ before they were placed between $\mathrm{Ni}$ and $\mathrm{Zn}$ electrodes. The resulting $\mathrm{Zn} / \mathrm{Ni} / \mathrm{Zn}$ electrode structure were tightly sealed between two mica plates under pressure. $\mathrm{NiZn}$ batteries with zinc electrodes having spherical $\mathrm{ZnO}$ particles synthesized from $\mathrm{ZnCl}_{2}$ (Sample dominate A1), plate-like $\mathrm{ZnO}$ particles synthesized $\mathrm{Zn}\left(\mathrm{NO}_{3}\right)_{2}$ (Sample $\mathrm{B} 1$ ), and commercial $\mathrm{ZnO}$ powder (Sample $\mathrm{Cl}$ ) were prepared using the same recipe. The schematic of prismatic batteries in which a Ni electrode is placed between two $\mathrm{Zn}$ electrodes is shown in Figure 1.

2.3. Characterization of Electrodes. The crystalline structure of commercial $\mathrm{ZnO}$ powder and $\mathrm{ZnO}$ powders prepared by precipitation methods and cycled zinc electrodes were characterized by powder X-ray diffraction (Phillips ${ }^{\mathrm{TM}}$ Xpert diffractometer with $\mathrm{Cu} K \alpha$ radiation) at a scan rate of $0.139 \mathrm{~s} \mathrm{~s}^{-1}$. Electron microscopy (FEI Quanta 250 equipped with an Oxford EDX system) was used to evaluate the morphology of $\mathrm{ZnO}$ powders and zinc electrodes before and after charge/discharge cycles. The surface area of $\mathrm{ZnO}$ powders was determined by Brunauer-Emmett-Teller (BET) analysis (Quantachrome Autosorb) with a nitrogen adsorption/desorption process.

2.4. Charge/Discharge Tests. Charge/discharge tests were performed using a DC power source (TT Technic RXN 305D), which works in either current or voltage limited mode, and a computerized battery analyzer (CBA IV 4 Pro). All tests were performed at room temperature. Charging of prismatic $\mathrm{NiZn}$ batteries was performed at fixed voltage $(1.94 \mathrm{~V})$ until charging current dropped to $0.01 \mathrm{~A}$. Discharge tests were done at $0.8 \mathrm{~A}$ fixed current until battery voltage dropped to $1.0 \mathrm{~V}$.

\section{Results and Discussions}

XRD patterns of commercial $\mathrm{ZnO}$ powder and $\mathrm{ZnO}$ powders synthesized from $\mathrm{ZnCl}_{2}$ and $\mathrm{Zn}\left(\mathrm{NO}_{3}\right)_{2} \cdot 6 \mathrm{H}_{2} \mathrm{O}$ are presented in Figure 2. XRD peaks of $\mathrm{ZnO}$ powder (wurtzite structure) at $2 \theta$ values of $31.77^{\circ}, 34.42^{\circ}, 36.25^{\circ}, 47.54^{\circ}, 56.59^{\circ}, 62.85^{\circ}$, $66.37^{\circ}, 67.94^{\circ}$, and $69.08^{\circ}$ correspond to (100), (002), (101), (102), (110), (103), (200), (112), and (201) planes, respectively (JCPDS-2 data file number: 79-2205). Detailed XRD analysis shows that synthesized powders contain $\mathrm{ZnO}$ only, and no trace of $\mathrm{Zn}(\mathrm{OH})_{2}$ is observed. It is also clear that the commercial $\mathrm{ZnO}$ powder has greater crystallinity compared to synthesized $\mathrm{ZnO}$ powders.

Figure 3 shows SEM images of $\mathrm{ZnO}$ powders synthesized from $\mathrm{ZnCl}_{2}$ and $\mathrm{Zn}\left(\mathrm{NO}_{3}\right)_{2} \cdot 6 \mathrm{H}_{2} \mathrm{O}$ as well as commercial $\mathrm{ZnO}$ powder. SEM images of $\mathrm{ZnO}$ powders synthesized from $\mathrm{ZnCl}_{2}$ show spherical particles that are between 20 and $40 \mathrm{~nm}$ in diameter. Compared with $\mathrm{ZnO}$ synthesized from $\mathrm{ZnCl}_{2}, \mathrm{ZnO}$ powder synthesized from $\mathrm{Zn}\left(\mathrm{NO}_{3}\right)_{2} \cdot 6 \mathrm{H}_{2} \mathrm{O}$ shows different morphology with plate-like structures and

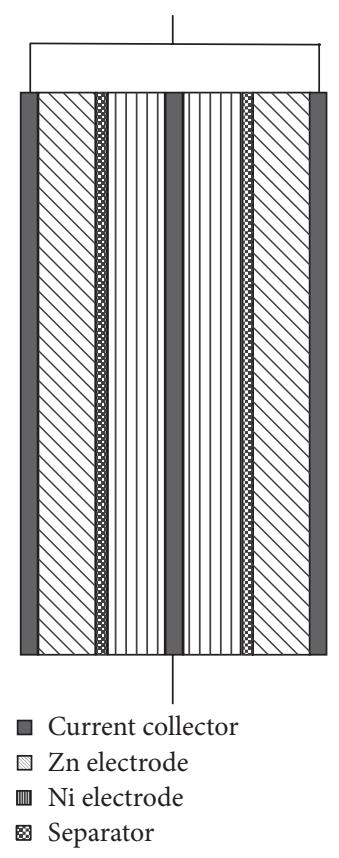

FIgUre 1: Schematic of prismatic NiZn battery consisting of one $\mathrm{Ni}$ and two Zn electrodes.

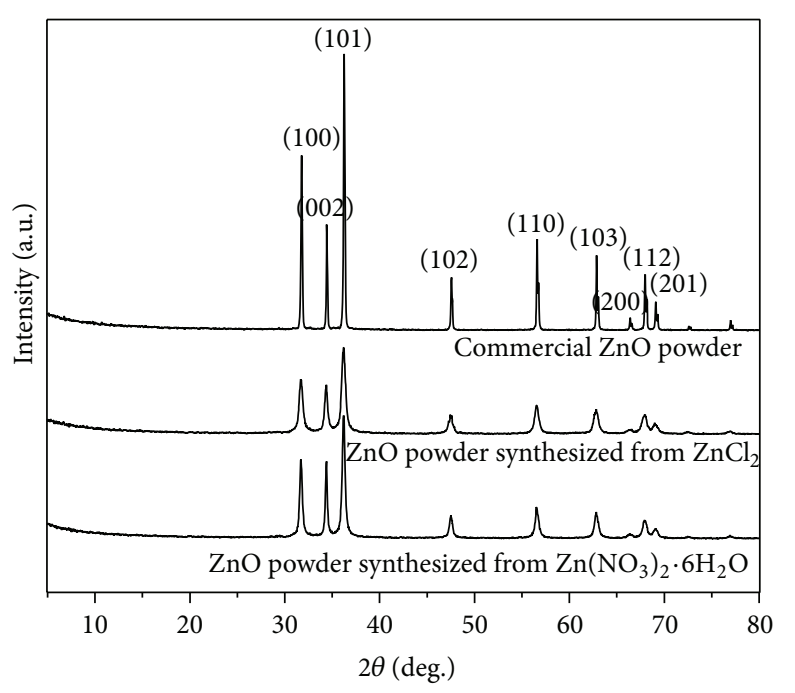

FIGURE 2: XRD patterns of commercial $\mathrm{ZnO}$ powder, $\mathrm{ZnO}$ powder synthesized from $\mathrm{ZnCl}_{2}$, and $\mathrm{ZnO}$ powder synthesized from $\mathrm{Zn}\left(\mathrm{NO}_{3}\right)_{2} \cdot 6 \mathrm{H}_{2} \mathrm{O}$.

nanosheets mixed with needle-like particles up to a micrometer in length, as seen in Figure 3(b). It is well known that nanosheets and nanotubes can be produced by controlling hydrothermal duration using $\mathrm{Zn}\left(\mathrm{NO}_{3}\right)_{2} \cdot 6 \mathrm{H}_{2} \mathrm{O}$ precursor [36-38]. The morphology of commercial $\mathrm{ZnO}$ synthesized by mechanochemical method is distinctly different than that of synthesized $\mathrm{ZnO}$ powders. A wide range of particle size distribution with a mixture of plates, rods, and prismatic particles up to several micrometers in length is observed in Figure 3(c). 


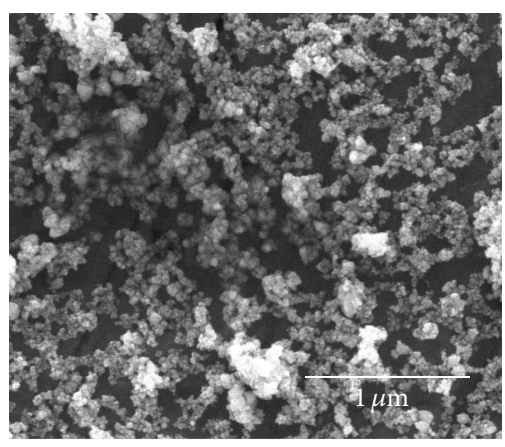

(a)

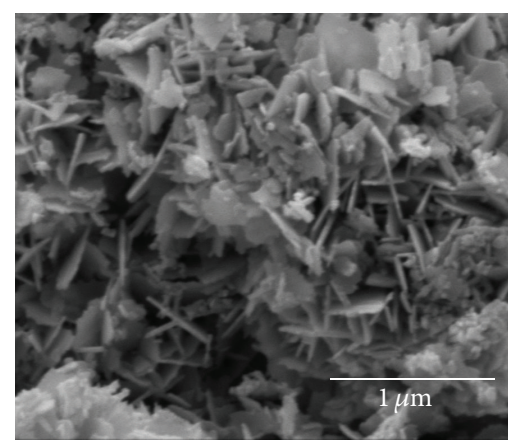

(b)

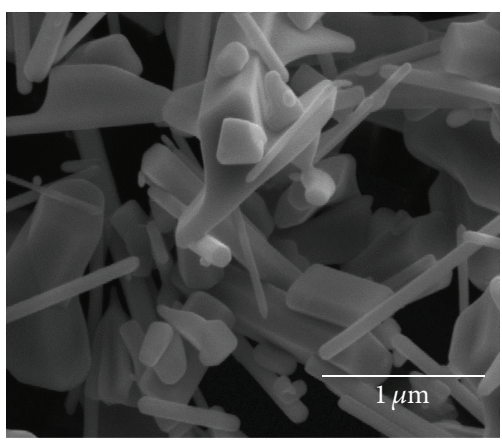

(c)

Figure 3: SEM images of (a) $\mathrm{ZnO}$ powder synthesized from $\mathrm{ZnCl}_{2}$, (b) $\mathrm{ZnO}$ powder synthesized from $\mathrm{Zn}\left(\mathrm{NO}_{3}\right)_{2} \cdot 6 \mathrm{H}_{2} \mathrm{O}$, and (c) commercial $\mathrm{ZnO}$.

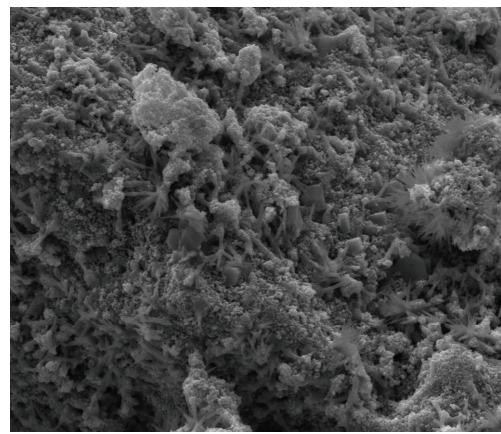

(a)

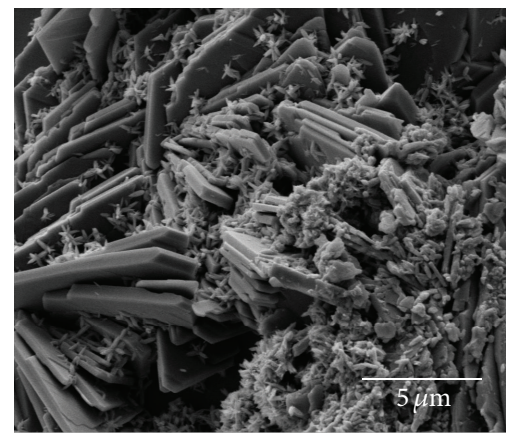

(b)

FIGURE 4: Morphology of zinc electrodes prepared using $\mathrm{ZnO}$ powder synthesized from $\mathrm{ZnCl}_{2}$ (Sample A1): (a) as-prepared and (b) after the third discharge.

Electrode surface area available for electrochemical reactions plays a key role in battery performance. In a NiZn battery, higher zinc electrode surface area should lead to enhanced materials utilization and higher power density and reduce passivation at high discharge rates [20]. Porous electrode structure provides higher energy density due to short ion transport length and easy charge transfer reaction on electrode-electrolyte interface [39-42]. Therefore, high surface area for a zinc electrode is desirable as it should improve battery performance by providing enhanced path lengths for both electron and $\mathrm{Zn}$ ion transport, electrode/electrolyte contact area, and accommodation of the strain of the $\mathrm{Zn}$ ion insertion/extraction [43, 44]. Surface areas of $\mathrm{ZnO}$ powders used in this study were calculated by Barrett-Joyner-Halenda (BJH) method. Spherical $\mathrm{ZnO}$ powder synthesized from $\mathrm{ZnCl}_{2}$ features a higher surface area of $26.05 \mathrm{~m}^{2} \mathrm{~g}^{-1}$ compared to plate-like $\mathrm{ZnO}$ powder synthesized from $\mathrm{Zn}\left(\mathrm{NO}_{3}\right)_{2} \cdot 6 \mathrm{H}_{2} \mathrm{O}\left(11.00 \mathrm{~m}^{2} \mathrm{~g}^{-1}\right)$ and commercial $\mathrm{ZnO}$ powder $\left(0.11 \mathrm{~m}^{2} \mathrm{~g}^{-1}\right)$. These results are lower than reported values in literature, $38.9 \mathrm{~m}^{2} \mathrm{~g}^{-1}$ for $\mathrm{ZnO}$ powder synthesized from $\mathrm{ZnCl}_{2}$ and $27.22 \mathrm{~m}^{2} \mathrm{~g}^{-1}$ for $\mathrm{ZnO}$ powder synthesized from $\mathrm{Zn}\left(\mathrm{NO}_{3}\right)_{2} \cdot 6 \mathrm{H}_{2} \mathrm{O}[34,35]$. However, these differences can be explained by variations in synthesis parameters (concentration, temperature, aging time, etc.).
In order to investigate the effect of initial morphology of $\mathrm{ZnO}$ powder on electrochemical performance, prismatic NiZn batteries were charged and discharged continuously. One set of the batteries were taken apart after the third discharge for evaluation of zinc electrode morphology change. During battery discharge, $\mathrm{OH}^{-}$ions near the electrode react with zinc to form soluble zincate ion $\left(\mathrm{Zn}(\mathrm{OH})_{4}{ }^{2-}\right)$. Zinc oxide is formed from zincate ion in the aqueous electrolyte when solubility limit is reached. The exact oxidation product of zinc is strongly related to $\mathrm{pH}$ value of the solution. However, with the test conditions used in this study, a passivating oxide layer, which reduces the capacity significantly, should not exist on the surface of zinc electrode during discharge $[45,46]$.

The microstructure and surface morphology of zinc electrode containing $\mathrm{ZnO}$ powder synthesized from $\mathrm{ZnCl}_{2}$ (Sample A1) are shown in Figure 4(a). Figure 4(b) shows the morphology of the same zinc electrode after the third discharge. After only three charge/discharge cycles, the morphology of zinc electrode was found to be different than the starting material in terms of both particle shape and size and porosity. $\mathrm{ZnO}$ nanospheres were mostly replaced with large $\mathrm{ZnO}$ plates and some needle-like $\mathrm{ZnO}$ particles. The microstructure evolution of zinc electrode prepared using $\mathrm{ZnO}$ powder synthesized from $\mathrm{Zn}\left(\mathrm{NO}_{3}\right)_{2} \cdot 6 \mathrm{H}_{2} \mathrm{O}$ (Sample B1) 


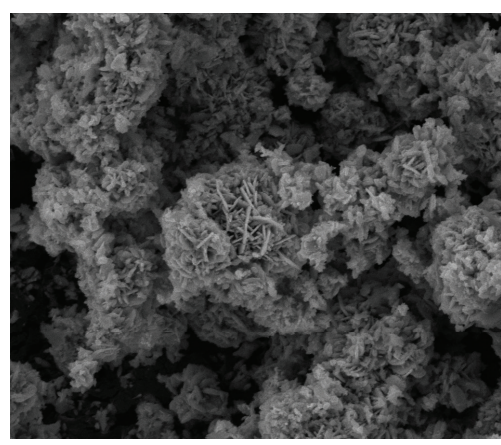

(a)

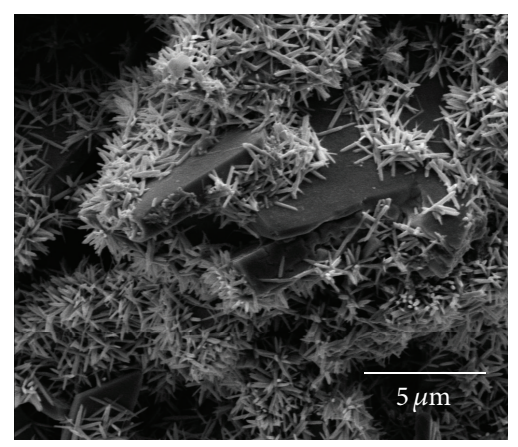

(b)

FIGURE 5: Morphology of zinc electrodes prepared using $\mathrm{ZnO}$ powder synthesized from $\mathrm{Zn}\left(\mathrm{NO}_{3}\right)_{2} \cdot 6 \mathrm{H}_{2} \mathrm{O}$ (Sample $\mathrm{B1}$ ): (a) as-prepared and (b) after the third discharge.

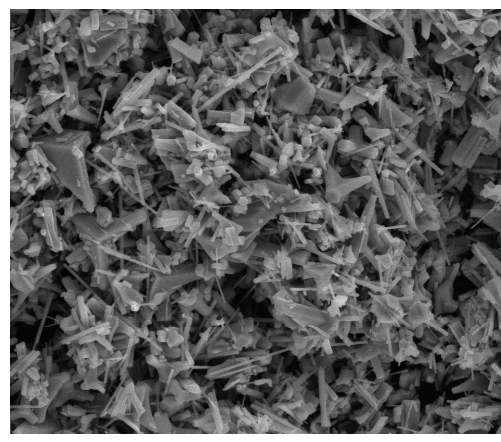

(a)

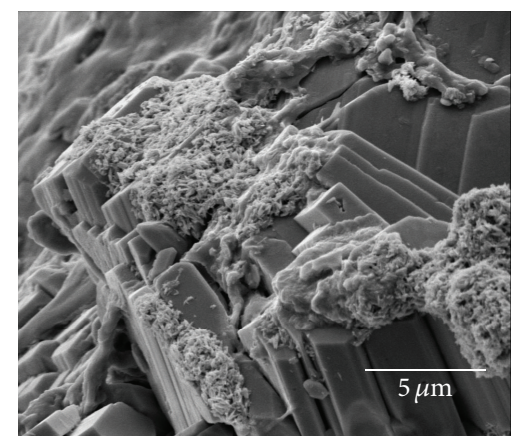

(b)

FIGURE 6: Morphology of zinc electrodes prepared using commercial $\mathrm{ZnO}$ powder (Sample C1): (a) as-prepared and (b) after the third discharge.

before the first charge and after the third discharge is shown in Figure 5. Similar to Sample A1, the morphology of Sample B1 after its third discharge was dramatically different than its initial morphology. Plate-like $\mathrm{ZnO}$ particles seen in asprepared sample were converted into micrometer size needles and wires as shown in Figure 5(b). In addition, in some large prismatic $\mathrm{ZnO}$ crystals a few micrometers in size were also observed. Finally, Figure 6 shows the SEM images of Sample $\mathrm{C} 1$ prepared using commercial $\mathrm{ZnO}$ as-prepared and after the third discharge. Again, the final morphology of the electrode after the third discharge was found to be very different than the starting electrode morphology. After the third discharge, very large $\mathrm{ZnO}$ crystals that were also observed in other samples covered most of the electrode surface. However, unlike other samples, $\mathrm{ZnO}$ nanowires or nanorods, or any indication of dendritic zinc growth, were not observed.

It should be noted that initial and subsequent charging of NiZn batteries do not convert zinc oxide into zinc metal completely, and there is always some unreacted $\mathrm{ZnO}$ powder. Therefore, during fabrication of commercial NiZn batteries, a common practice is to use at least $10 \%$ more $\mathrm{ZnO}$ powder than what is required for the desired capacity. The typical discharge curves of NiZn batteries are displayed in Figure 7. It should be noted again that the total amount of $\mathrm{ZnO}$ is $3 \mathrm{~g}$ for each zinc electrode (and a total of $6 \mathrm{~g}$ for a single NiZn battery) with a theoretical specific capacity of $978 \mathrm{mAh} \mathrm{g}^{-1}$ [47-49]. Since separator, electrolyte concentration, nickel electrode capacity, and all other experimental parameters are the same, voltage-capacity curves give valuable information about electrochemical behavior of zinc electrode. Batteries with zinc electrodes prepared by commercial $\mathrm{ZnO}$ powder (Sample C1) show a slower voltage drop from the initial point to approximately $1.35 \mathrm{~V}$ (discharge plateau) before a sharp voltage drop resulting in a higher discharge capacity, 2.06 Ah, compared to other samples with synthesized $\mathrm{ZnO}$ powders. In NiZn batteries with synthesized $\mathrm{ZnO}$ powders, Sample A1 and Sample B1 had 21\% and 8\% lower capacities, respectively. All batteries showed a similar discharge behavior; however, among multiple sample prepared, NiZn batteries with commercial $\mathrm{ZnO}$ powders consistently showed higher discharge capacities. With a $1.6 \mathrm{~V}$ nominal discharge voltage, NiZn batteries with synthesized $\mathrm{ZnO}$ powders showed average energy densities ranging between $92 \mathrm{Wh} \mathrm{kg}^{-1}$ and $109 \mathrm{Wh} \mathrm{kg}^{-1}$. NiZn batteries with commercial ZnO powders showed the highest energy density, $118 \mathrm{Wh} \mathrm{kg}^{-1}$.

While these average energy density values are relatively high, the results somewhat contradict previous studies in literature. It was reported that, using nano $\mathrm{ZnO}$ powders with carefully controlled morphologies in $\mathrm{Zn}$ electrodes, it is possible to obtain high average discharge capacities for 


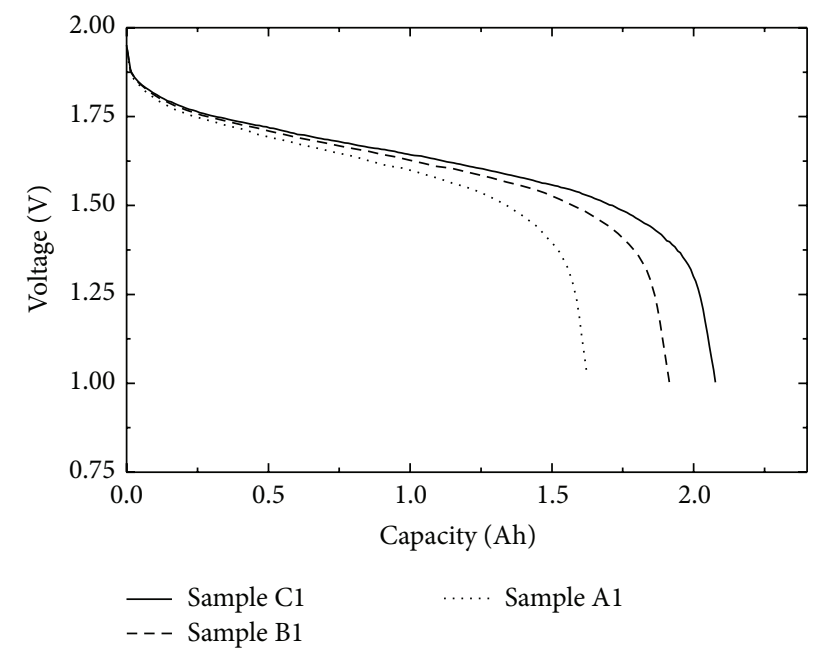

FIGURE 7: Discharge voltage versus capacity curves (at the third cycles) for NiZn batteries with $\mathrm{Zn}$ electrode prepared from (a) $\mathrm{ZnO}$ powder synthesized from $\mathrm{ZnCl}_{2}$ (Sample A1), (b) $\mathrm{ZnO}$ powder synthesized from $\mathrm{Zn}\left(\mathrm{NO}_{3}\right)_{2} \cdot 6 \mathrm{H}_{2} \mathrm{O}$ (Sample B1), and (c) commercial $\mathrm{ZnO}$ (Sample $\mathrm{C1})$.

zinc electrodes. For example, electrochemical activity of $\mathrm{ZnO}$ nanowires with average discharge capacity of $609 \mathrm{mAh} \mathrm{g}^{-1}$ was found to be superior to that of the conventional $\mathrm{ZnO}$ [32]. In a similar study, initial discharge capacities of hollow fusiform $\mathrm{ZnO}$ and hexagonal taper-like $\mathrm{ZnO}$ were reported to be $476 \mathrm{mAh} \mathrm{g}^{-1}$ and $470 \mathrm{mAh} \mathrm{g}^{-1}$, respectively [33]. However, the effect of zinc electrode discharge capacity on the battery energy density was not reported. While energy density values of prismatic NiZn batteries prepared in this study are much higher than average energy densities of commercially available NiZn batteries today, average discharge capacities of zinc electrodes vary between 270 and $345 \mathrm{~mA} \mathrm{~g}^{-1}$, much lower than reported values for nano $\mathrm{ZnO}$ powders in literature. Also, commercial $\mathrm{ZnO}$ powder with lowest surface area (Sample C1) showed better discharge capacity and led to higher energy density. Clearly, higher electrode surface area or higher electrode discharge capacity does not necessarily translate to higher energy density for NiZn batteries. To improve electrode discharge capacity, nano $\mathrm{ZnO}$ powders with carefully controlled morphologies need to be synthesized which usually increases fabrication costs. Another approach to increase the electrode discharge capacity is to use much thinner electrodes but this approach increases battery weight due to larger current collector and separator, leading to lower battery energy density. Contrary to previous studies, using conventional $\mathrm{ZnO}$ powder for zinc electrodes led to better cyclic stability. As seen in Figure 8, zinc electrodes with commercial $\mathrm{ZnO}$ powder showed less than $3 \%$ capacity loss after 50 cycles compared to $35 \%$ for Sample A1 and $8 \%$ for Sample B1, respectively.

At this point the reason for slightly higher discharge capacity and better discharge characteristics of zinc electrodes with commercial $\mathrm{ZnO}$ powder can only be interpreted to be related to the morphology of the $\mathrm{ZnO}$ powder. At the same time, SEM images reveal that initial morphology of the

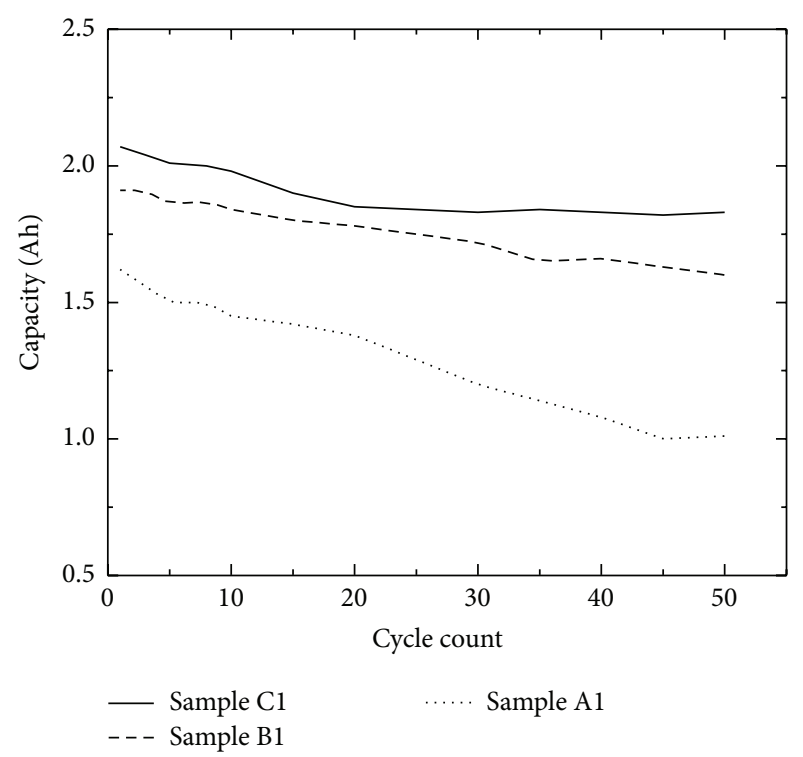

FIGURE 8: Variation of discharge capacity with charge/discharge cycle count for (a) $\mathrm{ZnO}$ powder synthesized from $\mathrm{ZnCl}_{2}$ (Sample A1), (b) $\mathrm{ZnO}$ powder synthesized from $\mathrm{Zn}\left(\mathrm{NO}_{3}\right)_{2} \cdot 6 \mathrm{H}_{2} \mathrm{O}$ (Sample B1), and (c) commercial ZnO (Sample C1).

electrodes changes drastically after a few charge/discharge cycles.

In literature, zinc electrodes prepared from hollow fusiform $\mathrm{ZnO}$ and hexagonal taper-like $\mathrm{ZnO}$ powders were reported to show and maintain high discharge capacity compared to conventional $\mathrm{ZnO}$ [33]. It was claimed that the morphology and orientation of zinc completely depend on surface characteristics of the substrate, and residual hollow fusiform $\mathrm{ZnO}$ and hexagonal taper-like $\mathrm{ZnO}$ powders are better substrates promoting lateral growth of active material crystal parallel to the substrate upon charging [33]. A similar change in morphology of zinc electrodes was also reported where electrochemical performance of commercial $\mathrm{ZnO}$ was compared to $\mathrm{ZnO}$ nanowires and nanosized $\mathrm{ZnO}[8,32]$. Contrary to findings in this study, NiZn batteries prepared with nanowire and nanosized $\mathrm{ZnO}$ were reported to show better discharge capacity and cycle stability, higher discharge voltage, and lower charge voltage. Better electrochemical performance was explained by substrate effects, electrochemical activity of $\mathrm{ZnO}$ particles, thickness of the electrodeposits, and the charge/discharge current density that usually favor nano $\mathrm{ZnO}$ particles in most NiZn batteries [8].

Actually, morphology of zinc electrode depends on many factors including but not limited to chemical and physical properties of the substrate, type and concentration of alkaline electrolyte, charge and discharge current densities, passive and active additives in electrode and electrolyte, electrode geometry, type and loading of binder material, temperature, and so forth. A small change in one or more of these parameters might result in different electrode morphology leading to a different discharge performance. The lower performance of electrodes with nanosized $\mathrm{ZnO}$ powders compared to electrodes with commercial $\mathrm{ZnO}$ powder should 
be related to zinc electrode morphology change since all other parameters are kept the same in this study.

As seen in Figures 4-6, even after only a few charge/discharge cycles, morphologies of zinc electrodes are different from each other, and they are also drastically different from their initial morphologies. Zinc electrode prepared with conventional hexagonal ZnO particles (Sample C1) shows very small amount of dendritic growth after charge/discharge cycles unlike electrodes with nanosized $\mathrm{ZnO}$ particles (Sample A1 and Sample B1). Dendritic growth is one of the issues related to poor performance of zinc electrodes. In addition, the surface areas reported here are the surface areas of $\mathrm{ZnO}$ powders used in preparation of zinc electrodes. Since after a few charge/discharge cycles electrode morphology changes drastically, erasing the initial morphology of the electrodes, the actual surface area of zinc electrode available for electrochemical reactions and porosity will be different as cycle count increases. We suspect that initial electrode composition and charge/discharge conditions used in this study result in a morphology change in which mass transport of zincate is diffusion limited leading to dendritic growth upon charging, and thus capacity loss for Sample A1 and Sample B1, batteries with zinc electrodes prepared from nano $\mathrm{ZnO}$ powders.

Studies on nanosized $\mathrm{ZnO}$ powders as electrode materials showing high electrode discharge capacities usually involve other additives in electrode structures such as fluoropolymer powders, graphite, acetylene black, $\mathrm{SnO}, \mathrm{In}_{2} \mathrm{O}_{3}$, and carboxymethylcellulose. In addition, $\mathrm{K}_{2} \mathrm{BO}_{3}, \mathrm{KF}, \mathrm{LiOH}$, and $\mathrm{NaOH}$ are also commonly used as alkaline electrolyte additives $[32,33]$. The type and amount of additives in electrode and electrolyte greatly affect electrochemical reactions, and therefore electrode morphology. It should be noted that zinc electrodes used in this study were prepared mixing zinc oxide powder with small amounts of calcium hydroxide, lead (II) oxide, cellulose, and PEG. Also $\mathrm{KOH}$ electrolyte had no additives to simplify the chemistry. It is possible that the absence of additives, which are proven to improve zinc electrode discharge capacity, is responsible for lower discharge capacities reported here.

\section{Conclusions}

There are many factors influencing NiZn battery performance such as battery geometry, separator, type and concentration of electrolyte, electrode porosities, gas evolution, initial charging conditions, and discharge current density. For example, the difference between average discharge capacities of zinc electrodes gets smaller and materials utilization is increased as the discharge current density is reduced. Initial morphology of zinc electrode seems to play a role in battery performance but it is unclear when the effect of initial morphology dominates the battery performance. Therefore, special attention must be paid to cell design and charge/discharge parameters, when comparing the effect of initial $\mathrm{ZnO}$ powder morphology on the battery performance.

Initial composition of zinc electrodes and battery testing conditions (charge and discharge current densities) used in this study are likely reasons for lower discharge capacities for zinc electrodes prepared with nanosized $\mathrm{ZnO}$ powders compared to reported values in literature. Clearly, initial morphology of zinc electrode has an effect on electrode discharge capacity but it might not be as important as one might think for the energy density of the battery. However, certain morphologies suppressing dendritic growth of zinc upon charging will certainly improve cycle life of $\mathrm{NiZn}$ batteries.

Passivation and short-circuiting are the main causes of limited cycle life of NiZn batteries but too often it is difficult to pinpoint which one is responsible for the capacity loss. A separator which suppresses the dendritic zinc growth and prevents shorting of battery, combined with electrolyte with low zincate solubility, is also necessary for improved cycle life and capacity.

The focus of most NiZn battery related research is on improving the performance of zinc electrode by increasing the electrode discharge capacity, reducing passivation, reducing shape change, and suppressing dendritic growth of zinc. While suppressing dendritic growth of zinc during charging to minimize the possibility of short-circuiting and reducing passivation is necessary, improving zinc electrode discharge capacity might not be necessary for reaching NiZn battery energy densities over $100 \mathrm{Wh} \mathrm{kg}^{-1}$ as shown in this study. Interestingly, there have not been any commercial NiZn batteries with energy densities over $100 \mathrm{Wh} \mathrm{kg}^{-1}$ in the market although zinc electrodes with extremely high discharge capacities have been fabricated. Extra weight and fabrication costs associated with these high performance zinc electrodes are main obstacles of commercialization. Therefore, electrode discharge density criteria must be used with caution.

\section{Competing Interests}

The authors declare that there are no competing interests regarding the publication of this paper.

\section{Acknowledgments}

The authors are thankful to Dr. Ogan Ocali and Professor Dr. Muhsin Çiftçioğlu for their valuable advice, comments, and discussions. They thank Ocalı A. S. for financial support to perform this work.

\section{References}

[1] H. Huang, L. Zhang, W. K. Zhang, Y. P. Gan, and H. Shao, "Preparation and electrochemical properties of $\mathrm{ZnO} /$ conductive-ceramic nanocomposite as anode material for $\mathrm{Ni} / \mathrm{Zn}$ rechargeable battery," Journal of Power Sources, vol. 184, no. 2, pp. 663-667, 2008.

[2] J. Cheng, L. Zhang, Y.-S. Yang, Y.-H. Wen, G.-P. Cao, and X.D. Wang, "Preliminary study of single flow zinc-nickel battery," Electrochemistry Communications, vol. 9, no. 11, pp. 2639-2642, 2007.

[3] J. Jindra, "Progress in sealed Ni-Zn cells, 1991-1995," Journal of Power Sources, vol. 66, no. 1-2, pp. 15-25, 1997. 
[4] J. Jindra, "Sealed Ni-Zn cells, 1996-1998," Journal of Power Sources, vol. 88, no. 2, pp. 202-205, 2000.

[5] A. K. Shukla, S. Venugopalan, and B. Hariprakash, "Nickelbased rechargeable batteries," Journal of Power Sources, vol. 100, no. 1-2, pp. 125-148, 2001.

[6] Y. F. Yuan, J. P. Tu, H. M. Wu, Y. Li, and D. Q. Shi, "Size and morphology effects of $\mathrm{ZnO}$ anode nanomaterials for $\mathrm{Zn} / \mathrm{Ni}$ secondary batteries," Nanotechnology, vol. 16, no. 6, pp. 803-808, 2005.

[7] M. Ma, J. P. Tu, Y. F. Yuan et al., "Electrochemical performance of $\mathrm{ZnO}$ nanoplates as anode materials for $\mathrm{Ni} / \mathrm{Zn}$ secondary batteries," Journal of Power Sources, vol. 179, no. 1, pp. 395-400, 2008.

[8] Y. F. Yuan, J. P. Tu, H. M. Wu, Y. Z. Yang, D. Q. Shi, and X. B. Zhao, "Electrochemical performance and morphology evolution of nanosized $\mathrm{ZnO}$ as anode material of Ni-Zn batteries," Electrochimica Acta, vol. 51, no. 18, pp. 3632-3636, 2006.

[9] P. Kritzer and J. A. Cook, "Nonwovens as separators for alkaline batteries," Journal of the Electrochemical Society, vol. 154, no. 5, pp. A481-A494, 2007.

[10] J. Philips and J. Zhao, "Method of manufacturing nickel zinc batteries," US Patent 7833663B2, 2010.

[11] M. Cai and S.-M. Park, "Spectroelectrochemical studies on dissolution and passivation of zinc electrodes in alkaline solutions," Journal of the Electrochemical Society, vol. 143, no. 7, pp. 21252131, 1996.

[12] J. McBreen, "Zinc plate shape change inhibition," Patent 3876470, 1975.

[13] Y. F. Yuan, J. P. Tu, H. M. Wu, Y. Li, D. Q. Shi, and X. B. Zhao, "Effect of $\mathrm{ZnO}$ nanomaterials associated with $\mathrm{Ca}(\mathrm{OH})_{2}$ as anode material for Ni-Zn batteries," Journal of Power Sources, vol. 159, no. 1, pp. 357-360, 2006.

[14] C.-C. Yang, W.-C. Chien, C. L. Wang, and C.-Y. Wu, "Study the effect of conductive fillers on a secondary $\mathrm{Zn}$ electrode based on ball-milled $\mathrm{ZnO}$ and $\mathrm{Ca}(\mathrm{OH})_{2}$ mixture powders," Journal of Power Sources, vol. 172, no. 1, pp. 435-445, 2007.

[15] Y. F. Yuan, L. Q. Yu, H. M. Wu et al., "Electrochemical performances of Bi based compound film-coated $\mathrm{ZnO}$ as anodic materials of Ni-Zn secondary batteries," Electrochimica Acta, vol. 56, no. 11, pp. 4378-4383, 2011.

[16] R. Shivkumar, G. P. Kalaignan, and T. Vasudevan, "Studies with porous zinc electrodes with additives for secondary alkaline batteries," Journal of Power Sources, vol. 75, no. 1, pp. 90-100, 1998.

[17] S.-H. Lee, C.-W. Yi, and K. Kim, "Characteristics and electrochemical performance of the $\mathrm{TiO}_{2}$-coated $\mathrm{ZnO}$ anode for $\mathrm{Ni}$ Zn secondary batteries," Journal of Physical Chemistry C, vol. 115, no. 5, pp. 2572-2577, 2011.

[18] D. Zeng, Z. Yang, S. Wang, X. Ni, D. Ai, and Q. Zhang, "Preparation and electrochemical performance of In-doped $\mathrm{ZnO}$ as anode material for Ni-Zn secondary cells," Electrochimica Acta, vol. 56, no. 11, pp. 4075-4080, 2011.

[19] M. Hilder, B. Winther-Jensen, and N. B. Clark, "The effect of binder and electrolyte on the performance of thin zinc-air battery," Electrochimica Acta, vol. 69, pp. 308-314, 2012.

[20] M. N. Masri, M. F. M. Nazeri, C. Y. Ng, and A. A. Mohamad, "Tapioca binder for porous zinc anodes electrode in zincair batteries," Journal of King Saud University-Engineering Sciences, vol. 27, no. 2, pp. 217-224, 2015.

[21] C. W. Lee, S. W. Eom, K. Sathiyanarayanan, and M. S. Yun, "Preliminary comparative studies of zinc and zinc oxide electrodes on corrosion reaction and reversible reaction for zinc/air fuel cells," Electrochimica Acta, vol. 52, no. 4, pp. 1588-1591, 2006.

[22] S. Müller, F. Holzer, and O. Haas, "Optimized zinc electrode for the rechargeable zinc-air battery," Journal of Applied Electrochemistry, vol. 28, no. 9, pp. 895-898, 1998.

[23] G. M. Wu, S. J. Lin, and C. C. Yang, "Alkaline Zn-air and Alair cells based on novel solid PVA/PAA polymer electrolyte membranes," Journal of Membrane Science, vol. 280, no. 1-2, pp. 802-808, 2006.

[24] C.-C. Yang and S.-J. Lin, "Alkaline composite PEO-PVA-glassfibre-mat polymer electrolyte for Zn-air battery," Journal of Power Sources, vol. 112, no. 2, pp. 497-503, 2002.

[25] M. N. Masri and A. A. Mohamad, "Effect of adding potassium hydroxide to an agar binder for use as the anode in $\mathrm{Zn}$-air batteries," Corrosion Science, vol. 51, no. 12, pp. 3025-3029, 2009.

[26] T. Cohen-Hyams, Y. Ziengerman, and Y. Ein-Eli, "In situ STM studies of zinc in aqueous solutions containing PEG DiAcid inhibitor: correlation with electrochemical performances of zinc-air fuel cells," Journal of Power Sources, vol. 157, no. 1, pp. 584-591, 2006.

[27] H. Zhou, Q. Huang, M. Liang et al., "Investigation on synergism of composite additives for zinc corrosion inhibition in alkaline solution," Materials Chemistry and Physics, vol. 128, no. 1-2, pp. 214-219, 2011.

[28] Y. Ein-Eli, M. Auinat, and D. Starosvetsky, "Electrochemical and surface studies of zinc in alkaline solutions containing organic corrosion inhibitors," Journal of Power Sources, vol. 114, no. 2, pp. 330-337, 2003.

[29] A. Kolodziejczak-Radzimska and T. Jesionowski, "Zinc oxidefrom synthesis to application: a review," Materials, vol. 7, no. 4, pp. 2833-2881, 2014.

[30] R. Wahab, Y.-S. Kim, K. Lee, and H.-S. Shin, "Fabrication and growth mechanism of hexagonal zinc oxide nanorods via solution process," Journal of Materials Science, vol. 45, no. 11, pp. 2967-2973, 2010.

[31] H. M. Deng, J. Ding, Y. Shi, X. Y. Liu, and J. Wang, "Ultrafine zinc oxide powders prepared by precipitation/mechanical milling," Journal of Materials Science, vol. 36, no. 13, pp. 32733276, 2001.

[32] J. L. Yang, Y. F. Yuan, H. M. Wu, Y. Li, Y. B. Chen, and S. Y. Guo, "Preparation and electrochemical performances of $\mathrm{ZnO}$ nanowires as anode materials for $\mathrm{Ni} / \mathrm{Zn}$ secondary battery," Electrochimica Acta, vol. 55, no. 23, pp. 7050-7054, 2010.

[33] R. J. Wen, Z. H. Yang, X. Fan, Z. Tan, and B. Yang, "Electrochemical performances of $\mathrm{ZnO}$ with different morphology as anodic materials for $\mathrm{Ni} / \mathrm{Zn}$ secondary batteries," Electrochimica Acta, vol. 83, pp. 376-382, 2012.

[34] Y.-L. Wei and P.-C. Chang, "Characteristics of nano zinc oxide synthesized under ultrasonic condition," Journal of Physics and Chemistry of Solids, vol. 69, no. 2-3, pp. 688-692, 2008.

[35] S. Musić, D. Dragčević, and S. Popović, "Influence of synthesis route on the formation of $\mathrm{ZnO}$ particles and their morphologies," Journal of Alloys and Compounds, vol. 429, no. 1-2, pp. 242249, 2007.

[36] A. E. Suliman, Y. Tang, Z. Xin, and Z. Jia, "The effect of PVP addition and heat-treatment duration on zinc oxide nanoparticles," Journal of Applied Sciences, vol. 6, no. 6, pp. 1298-1301, 2006.

[37] A. Elkhidir Suliman, Y. Tang, and L. Xu, "Preparation of $\mathrm{ZnO}$ nanoparticles and nanosheets and their application to dyesensitized solar cells," Solar Energy Materials and Solar Cells, vol. 91, no. 18, pp. 1658-1662, 2007. 
[38] Y. Sun, N. G. Ndifor-Angwafor, D. J. Riley, and M. N. R. Ashfold, "Synthesis and photoluminescence of ultra-thin $\mathrm{ZnO}$ nanowire/nanotube arrays formed by hydrothermal growth," Chemical Physics Letters, vol. 431, no. 4-6, pp. 352-357, 2006.

[39] C. M. A. Brett and A. M. O. Brett, Electrochemistry: Principles, Methods, and Applications, Oxford University Press, Oxford, UK, 1st edition, 1994.

[40] E. Gileadi, Electrode Kinetics for Chemists, Chemical Engineers, and Materials Scientists, John Wiley \& Sons, 1st edition, 1993.

[41] M. Minakshi, D. Appadoo, and D. E. Martin, "The anodic behavior of planar and porous zinc electrodes in alkaline electrolyte," Electrochemical and Solid-State Letters, vol. 13, no. 7, pp. A77-A80, 2010.

[42] T. Chen, L. Pan, T. A. J. Loh et al., "Porous nitrogen-doped carbon microspheres as anode materials for lithium ion batteries," Dalton Transactions, vol. 43, no. 40, pp. 14931-14935, 2014.

[43] H.-W. Shim, D. K. Lee, I.-S. Cho, K. S. Hong, and D.-W. Kim, "Facile hydrothermal synthesis of porous $\mathrm{TiO}_{2}$ nanowire electrodes with high-rate capability for Li ion batteries," Nanotechnology, vol. 21, no. 25, Article ID 255706, 2010.

[44] A. S. Aricò, P. Bruce, B. Scrosati, J.-M. Tarascon, and W. Van Schalkwijk, "Nanostructured materials for advanced energy conversion and storage devices," Nature Materials, vol. 4, no. 5, pp. 366-377, 2005.

[45] P. Sapkota and H. Kim, "Zinc-air fuel cell, a potential candidate for alternative energy," Journal of Industrial and Engineering Chemistry, vol. 15, no. 4, pp. 445-450, 2009.

[46] D. Linden, Handbook of Batteries, McGraw-Hill, New York, NY, USA, 2nd edition, 1995.

[47] L.-L. Xu, S.-W. Bian, and K.-L. Song, "Graphene sheets decorated with $\mathrm{ZnO}$ nanoparticles as anode materials for lithium ion batteries," Journal of Materials Science, vol. 49, no. 18, pp. 62176224, 2014.

[48] X. Shen, D. Mu, S. Chen, B. Wu, and F. Wu, "Enhanced electrochemical performance of $\mathrm{ZnO}$-loaded/porous carbon composite as anode materials for lithium ion batteries," ACS Applied Materials \& Interfaces, vol. 5, no. 8, pp. 3118-3125, 2013.

[49] X. H. Huang, J. B. Wu, Y. Lin, and R. Q. Guo, “ZnO microrod arrays grown on copper substrates as anode materials for lithium ion batteries," International Journal of Electrochemical Science, vol. 7, no. 8, pp. 6611-6621, 2012. 

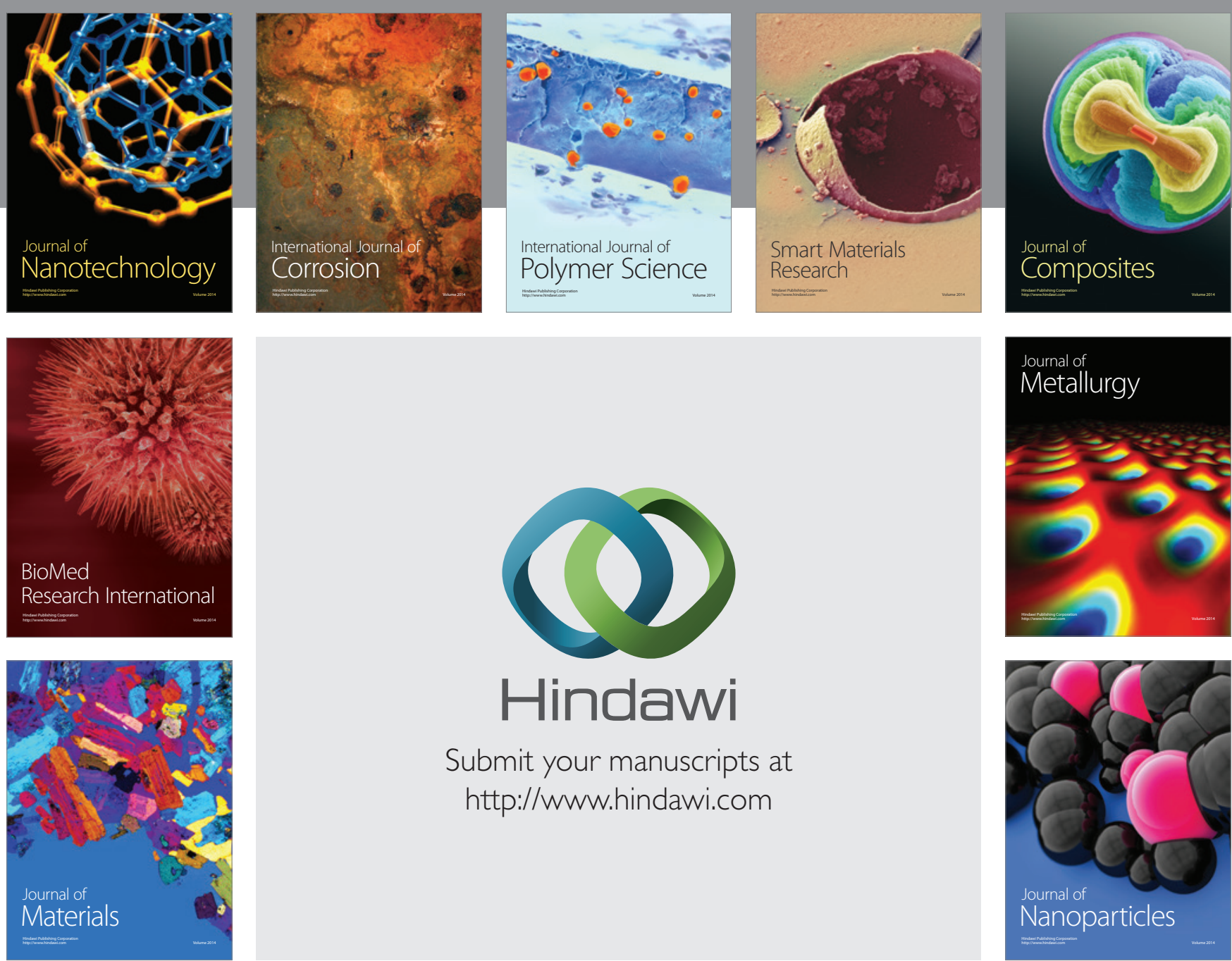

\section{Hindawi}

Submit your manuscripts at

http://www.hindawi.com

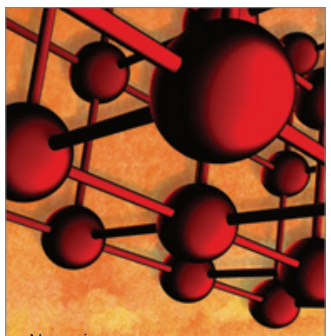

Materials Science and Engineering
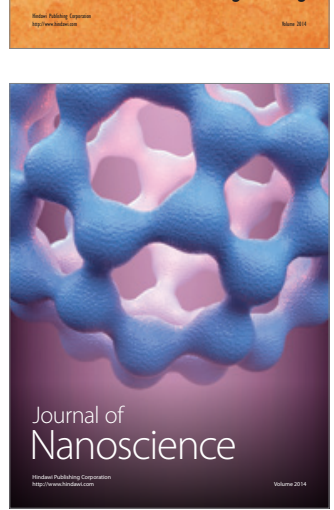
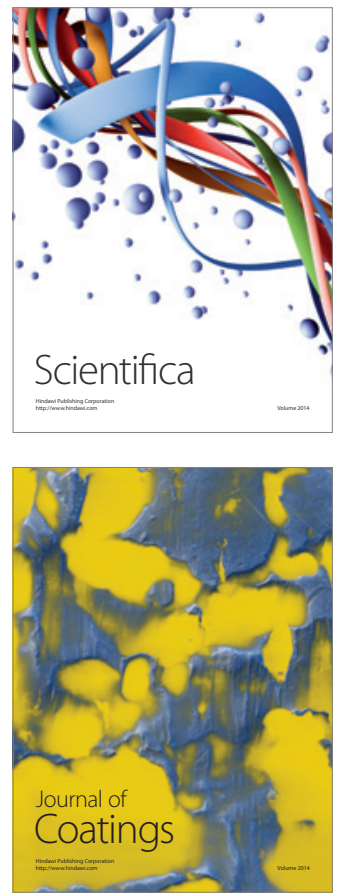
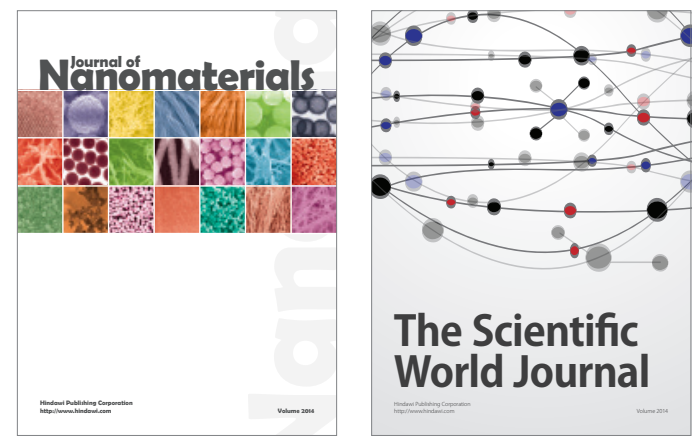

The Scientific World Journal
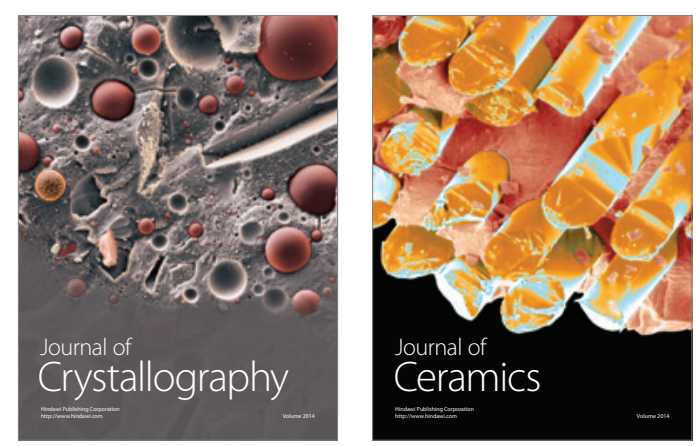
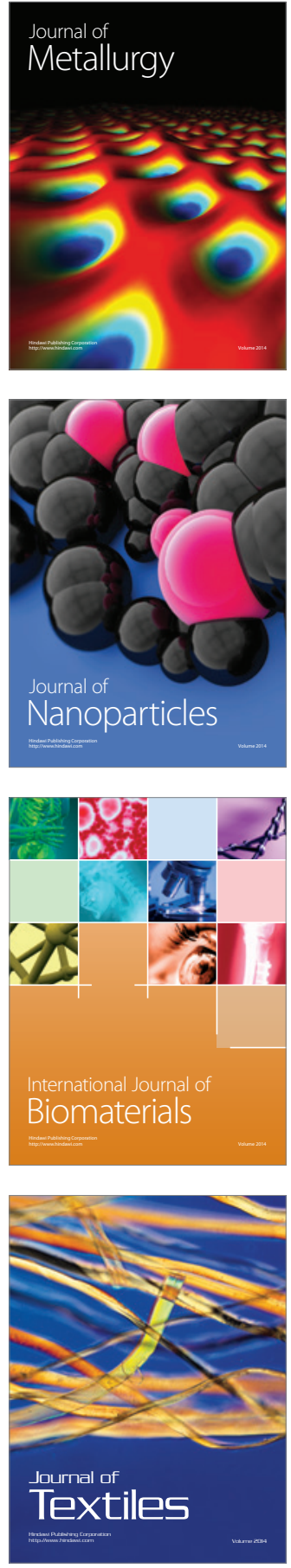